\title{
The use of the SMED method in improvement of production enterprises
}

\author{
Joanna Stuglik ${ }^{1}$, Zofia Gródek-Szostak ${ }^{2}$, and Danuta Kajrunajtys ${ }^{3}$ \\ ${ }^{1}$ Lesser Poland State University Captain Witold Pilecki, ul. M. Kolbego 8, 32-600 Oświęcim, Poland \\ ${ }^{2}$ Cracow University of Economics, 31-510 Kraków, Rakowicka 27, Poland \\ ${ }^{3}$ Cracow University of Economics, 31-510 Kraków, Rakowicka 27, Poland
}

\begin{abstract}
The aim of the paper is to present the results of introducing the SMED method on one of the production lines in a selected production company. For the purposes of this study, a single bottling line for filling $200 \mathrm{ml}$ and $250 \mathrm{ml}$ glass bottles with carbonated drinks was selected. Upon analyzing the process of mixer washing in terms of time, it was shown that in individual steps, the total single washing time was 5 hours 3 minutes on average, which accounted for about $19 \%$ of the total retooling of the production line. However, after using the SMED method, this process has taken 3 hours 50 minutes. Thus, a saving of 1 hour 13 minutes was obtained after shortening the retooling, which allowed to extend the production process.
\end{abstract}

\section{Introduction}

The literature describes retooling as the time needed to change various parameters and parts of machines, as well as staff, which adds no value for the end customer. It is a process that begins when the last product from group $\mathrm{A}$ has been manufactured, and lasts until the first correct product from group B has been manufactured [1]. For manufacturing enterprises, which have grown on Toyota rules, this process was classified as a necessary waste. Therefore, it was also noted that the retooling time can be repeatedly reduced by using appropriate LM techniques [2]. This method was called SMED, and was considered a highly important tool in terms of lean production. Literature has defined it as reducing the time of retooling of a single machine. The main goal of SMED was to reduce retooling to under 10 minutes [3]. The starting point of this method is to realize that each retooling can be done differently than before, mainly in such a way that brings the greatest profit from the point of view of the company [3,4]. Following a change in the way of thinking, it was noticed that even the most monotonous activities can be changed. The creator of SMED, Shingeo Shingo has established four stages for quick retooling:

I. Preparation - measurement and recording of the status quo;

II. Division of operations into external and internal;

III. Transforming internal activities into external;

IV. Improving all conversion components [5]. 
The essence of the method is to replace the so-called internal activities with external and to maintain this state of affairs by continuous improvement of operations.

Carrying out the SMED project on the production line brings the company the greatest benefits from the lean manufacturing perspective. First of all, it increases the company's flexibility in managing inventory when executing customer orders, generates faster production in smaller batches and better quality products by reducing the amount of operational inventory and defects related to machine setup [4,6]. What is most important, however, SMED increases the efficiency of the production line due to greater machine availability. The risk of accidents is also reduced, which means improved work safety [4]. Please note that all of the above elements significantly reduce production costs. The aim of the paper is to present the results of introducing the SMED method on one of the production lines in a selected production company.

\section{Methodology}

The selected production company has five bottling lines for beverages: for PET and glass bottles, and aluminum cans. Each of them produces beverages of different sizes and flavors, which means a great need for changeovers. The production plant has a well-developed production process control system, which facilitates swift and effective detection and elimination of deficits or waste. The lines work in a counter pressure system, using KANBAN cards. This is the method in which the order placed by the customer significantly affects the production process, i.e. activities performed at the end of the value stream report the needs to previous positions. The system's aim is to eliminate unnecessary overproduction and operational inventory.

For the purposes of this study, a single bottling line for filling $200 \mathrm{ml}$ and $250 \mathrm{ml}$ glass bottles with carbonated drinks was selected. The line consists of thirteen fully functional machines, serviced by eight qualified production operators. Two production formats and four flavors require frequent and time-consuming retooling. Therefore, the shortening operations should be carried out at designated intervals. To meet its needs, the production plant has set an annual deadline for commissioning the SMED project, depending on the greatest demand. The machines in this production line have a specific capacity imposed by the manufacturer. More important, however, is their actual capacity as it adopts realistic, analyzed values and determines places called bottlenecks on its basis. This production line parameter is shown in Table 1.

Table 1. Actual and theoretical capacity of the production line

\begin{tabular}{|c|c|c|c|c|}
\hline \multirow{2}{*}{ Machine } & \multicolumn{2}{|c|}{$\begin{array}{c}\text { Machine's actual capacity } \\
\text { (Pcs*h }^{-1)}\end{array}$} & \multicolumn{2}{c|}{$\begin{array}{c}\text { Maximum capacity } \\
\text { (Pcs*h }\end{array}$} \\
\cline { 2 - 5 } & $\mathbf{2 0 0} \mathbf{~ m l ~ f o r m a t ~}$ & $\begin{array}{c}\mathbf{2 5 0} \text { ml } \\
\text { format }\end{array}$ & 200 ml format & $\begin{array}{c}\mathbf{2 5 0} \text { ml } \\
\text { format }\end{array}$ \\
\hline DEPALLETIZER & 40,320 & 40,320 & 44,352 & 44,352 \\
\hline $\begin{array}{c}\text { UNPACKING } \\
\text { MACHINE }\end{array}$ & 36,000 & 36,000 & 38,400 & 38,400 \\
\hline BOTTLE WASHER & 42,000 & 42,000 & 55,000 & 55,000 \\
\hline
\end{tabular}




\begin{tabular}{|c|c|c|c|c|}
\hline FILLER & 34,000 & 30,000 & 37,500 & 37,500 \\
\hline LABELLER & 35,500 & 35,500 & 38,500 & 38,500 \\
\hline $\begin{array}{c}\text { PACKING } \\
\text { MACHINE }\end{array}$ & 36,000 & 36,000 & 38,400 & 38,400 \\
\hline PALLETIZER & 35,000 & 35,000 & 38,016 & 38,016 \\
\hline
\end{tabular}

It should be mentioned that the actual capacity was calculated following the analysis of the current state of the production line. As demonstrated by the results, the line's capacity doesn't change depending on the product format; only slight fluctuations are noticeable in the bottling machine. Even at this stage of research it can be determined which of the machines has the lowest and the highest production capacity, and thus determine which of them is the bottleneck. In each case, the culprit was the filler, which pours the product into a bottle.

In order to apply the above method, it was necessary to meticulously carry out a number of controlling and continuous improvement activities, as well as to review all four stages of SMED implementation. Initially, research and assessment of the production line condition were undertaken to observe major material and time losses. After several days of observation and collecting relevant data, the following material and time losses were determined (Table 2):

Table 2. Time and material losses on the production line.

\begin{tabular}{|c|c|}
\hline Material losses of the line & Time losses of the line \\
\hline \multirow{4}{*}{$\begin{array}{l}\text { Losses due to shortages: } \\
\text { •deficiencies } \\
\text { •pops } \\
\text { •poor quality of bottles }\end{array}$} & retooling time \\
\hline & breakdown time \\
\hline & washing time \\
\hline & operational standbys and emergencies \\
\hline
\end{tabular}

Material losses were counted in pieces, while time losses in hours. Due to the nature of the SMED project, the focus was mainly on hourly losses, in order to optimize the duration of one of the processes. Finally, the impact of the implemented SMED project on production line resource efficiency indicators was analyzed.

The production line area and the machine subject to SMED project was selected, based on Pareto diagrams. The mixer, a machine used to mix individual components of a carbonated drink (i.e.: syrup, water, sugar and carbon dioxide with air), became the object of improvement. Pilot retooling activities and reducing its duration were carried out in accordance with the SMED project assumptions carried out in the company in question.

\section{Research results}

The first stage of the analysis was to establish the SMED project team, which included four people. Of these, two members were selected to observe the status quo of the mixer washing process in the visualization program. The time of starting the retooling was also taken into account, marked by the moment of ending the production of another flavor. The tables (table 3,4,5) summarize all actions involved in the mixer washing process, divided into three most important steps. 
Table 3. Activities in Step I of mixer washing, including its duration

\begin{tabular}{|c|c|c|c|c|}
\hline No. & Step 1 & Start & End & Duration \\
\hline 1 & Rinsing & $02: 50$ & 03:02 & $00: 12$ \\
\hline 2 & $\begin{array}{c}\text { Flushing water with a hot water solution injected into the } \\
\text { washed object }\end{array}$ & 03:02 & 03:03 & 00:01 \\
\hline 3 & Filling the object with hot water from the tank & 03:03 & $03: 13$ & $00: 10$ \\
\hline 4 & Hot water circulation and heating of the solution & 03:13 & 03:17 & 00:04 \\
\hline 5 & Hot water sterilization & 03:17 & 03:36 & $00: 19$ \\
\hline 6 & $\begin{array}{c}\text { Flushing hot water with water injected into the washed } \\
\text { object }\end{array}$ & 03:36 & $03: 46$ & $00: 10$ \\
\hline 7 & Rinsing with fresh water into the drain & $03: 46$ & 04:01 & $00: 15$ \\
\hline \multirow[t]{2}{*}{8} & Discharging fresh water from the washed object & 04:01 & 04:07 & 00:06 \\
\hline & & & Total & 01:17 \\
\hline
\end{tabular}

Table 4. Activities in Step II of mixer washing, including its duration

\begin{tabular}{|c|c|c|c|c|}
\hline No. & Step 2 & Start & End & Duration \\
\hline 1 & Rinsing with fresh water & $01: 45$ & $01: 56$ & $00: 11$ \\
\hline 2 & $\begin{array}{c}\text { Flushing water with an alkaline solution injected into the } \\
\text { washed object }\end{array}$ & $01: 56$ & $01: 57$ & $00: 01$ \\
\hline 3 & $\begin{array}{c}\text { Flushing water out of the washed circuit - discharging into the } \\
\text { drain }\end{array}$ & $01: 57$ & $02: 02$ & $00: 05$ \\
\hline 4 & $\begin{array}{c}\text { Filling the object with an alkaline solution - return to the } \\
\text { washing pit }\end{array}$ & $02: 02$ & $02: 08$ & $00: 06$ \\
\hline 5 & $\begin{array}{c}\text { Circulation of an alkaline solution and adding concentrated } \\
\text { llkaline }\end{array}$ & $02: 08$ & $02: 11$ & $00: 03$ \\
\hline 6 & Alkaline circulation and heating of the solution & $02: 11$ & $02: 16$ & $00: 05$ \\
\hline 7 & Alkaline washing & $02: 16$ & $02: 40$ & $00: 24$ \\
\hline 8 & $\begin{array}{c}\text { Flushing the alkaline with water injected into the washed } \\
\text { circuit }\end{array}$ & $02: 40$ & $02: 41$ & $00: 01$ \\
\hline 9 & $\begin{array}{c}\text { Flushing the alkaline with water injected into the washed } \\
\text { circuit }\end{array}$ & $02: 41$ & $02: 46$ & $00: 05$ \\
\hline 10 & Rinsing with fresh water into the drain & $02: 46$ & $02: 54$ & $00: 08$ \\
\hline 11 & Rinsing with fresh water into the drain & $02: 54$ & $03: 06$ & $00: 12$ \\
\hline 12 & Draining the washed object of fresh water & $03: 06$ & $03: 12$ & $00: 06$ \\
\hline & & & Total & $\mathbf{0 1 : 2 7}$ \\
\hline
\end{tabular}


Table 5. Activities in Step II of mixer washing, including its duration

\begin{tabular}{|c|c|c|c|c|}
\hline No. & Step 3 & Start & End & Duration \\
\hline 1 & Rinsing & $23: 57$ & $00: 09$ & $00: 12$ \\
\hline 2 & Flushing water with an alkaline solution injected into the & $00: 09$ & $00: 16$ & $00: 07$ \\
\hline 3 & washed object - discharge & $00: 16$ & $00: 22$ & $00: 06$ \\
\hline 4 & Filling the object with an alkaline solution & $00: 22$ & $00: 26$ & $00: 04$ \\
\hline 5 & Circulation of the alkaline & $00: 26$ & $00: 47$ & $00: 21$ \\
\hline 6 & Alkaline washing & $00: 47$ & $00: 54$ & $00: 07$ \\
\hline 7 & Intermediate rinsing with fresh water into the drain & $00: 54$ & $01: 08$ & $00: 14$ \\
\hline 8 & Flushing water with a hot water solution injected into the & $01: 08$ & $01: 09$ & $00: 01$ \\
\hline 9 & washed object & $01: 09$ & $01: 18$ & $00: 09$ \\
\hline 10 & Filling the object with hot water from the tank & $01: 18$ & $01: 25$ & $00: 07$ \\
\hline 11 & Circulation of hot water & $01: 25$ & $01: 45$ & $00: 20$ \\
\hline 12 & Flushing hot water with water injected into the washed object & $01: 45$ & $01: 55$ & $00: 10$ \\
\hline 13 & Rinsing with fresh water into the drain & $01: 55$ & $02: 09$ & $00: 14$ \\
\hline 14 & Discharge & $02: 09$ & $02: 16$ & $00: 07$ \\
\hline & & & Total & $\mathbf{0 2 : 1 9}$ \\
\hline
\end{tabular}

Referring to the above tables, it was observed that some of the actions performed in individual steps occur consecutively in the system, therefore, the next action could not start until the previous one has been executed. Considering the average monthly retooling time, i.e. $24.43(\mathrm{~h})$ and the mixer washing time alone, which was $6.31^{\left(\mathrm{h}^{*} \text { month-1)}\right.}$, as well as production time, $201.4^{\left(\mathrm{h}^{*} \text { month-1) }\right.}$, it was noticed that $11 \%$ of the operating time was dedicated to retooling, with $21 \%$ for washing the device alone.

In Stage II, the operations performed in individual retooling steps were divided. As mentioned before, the process of washing the mixer was not overly complicated, but it turned out to be time-consuming due to the consecutive actions. To remedy this, a twoperson team was established, whose goal was to find and analyze time savings using the PLC program and a visualization system. The mixer operation program prior to improvements was summarized in Table 6 .

Table 6. Stepwise process of washing the mixer in the old system

\begin{tabular}{|c|c|}
\hline Step & The process of washing the mixer in the old system \\
\hline \multirow{4}{*}{ Step 2 } & Filling the B2 tank with a syrup route \\
\cline { 2 - 3 } & Washing tanks B2, B3, and B1 (mixer) from tank B1 \\
\cline { 2 - 2 } & Open valves: $1,4,5,7,9,16,18,59,60,67,70,71$ \\
\hline \multirow{4}{*}{ Step 4 } & Running pumps: P1, P4 \\
\cline { 2 - 2 } & Filling B3 by P1 pump from B1 \\
\cline { 2 - 2 } & Washing the B5 tank via the mixer and the syrup path \\
\cline { 2 - 2 } & Open valves: $6,7,8,13,14,15,16,17,59,60,67,70,71$ \\
\hline \multirow{4}{*}{ Step 7 } & Running pumps: P1, P4 \\
\cline { 2 - 2 } & The P3 pump moves the medium to the B6 tank until it reaches the upper level (false \\
& signals - splashing from the tank) \\
\hline \multirow{3}{*}{ Step 8 } & B1 filled to the maximum from the CIP station \\
\cline { 2 - 2 } & Discharge from B5 to B6 \\
\hline
\end{tabular}

After a thorough analysis of the washing process shown in Tab. 6, the following ideas were proposed to improve the system: 
1. Transferring part of the B5 tank washing from step 4 to 2 , to ensure the same wash time.

2. Shorter refilling of tank B3 in step 4, which is filled in step 8,

3. Pumping with pump P3 to tank B6, regardless of the status of the upper level sensor in step 7.

4. Filling tank B3 to the set value (approx. half of the tank).

5. Other steps unchanged.

The next step was to check whether the system will work in the desired way after the implementation of the ideas. The effects are presented in Tab. 7

Table 7. The effects of introducing changes in the mixer washing process

\begin{tabular}{|c|c|c|c|}
\hline Step & The old washing process & $\begin{array}{c}\text { The new washing process } \\
\text { (changes) }\end{array}$ & Benefit \\
\hline \multirow{4}{*}{ Step 2} & Filling the $\mathrm{B} 2$ tank via the syrup route & $\begin{array}{l}\text { Filling the B2 tank via the syrup } \\
\text { route }\end{array}$ & \multirow{4}{*}{$\begin{array}{l}\text { Washing the } \\
\text { B5 tank was } \\
\text { transferred } \\
\text { from step 4, to } \\
\text { ensure the } \\
\text { same washing } \\
\text { time }\end{array}$} \\
\hline & $\begin{array}{l}\text { Washing tanks B2, B3, and B1 (mixer) } \\
\text { from tank B1 }\end{array}$ & $\begin{array}{l}\text { Washing tanks B5, B2, B3, and } \\
\text { B1 (mixer) from tank B1 }\end{array}$ & \\
\hline & $\begin{array}{c}\text { Open valves: } 1,4,5,7,9,16,18,59,60 \\
67,70,71\end{array}$ & $\begin{array}{c}\text { Open valves: } 1,4,5,7, \mathbf{8}, 9,16 \\
18,59,60,67,70,71\end{array}$ & \\
\hline & Running pumps: P1, P4 & Running pumps: $\mathrm{P} 1, \mathrm{P} 4$ & \\
\hline \multirow{4}{*}{ Step 4} & Filling B3 by P1 pump from B1 & Filling B3 with P1 pump from B1 & $\begin{array}{l}\text { Shorter } \\
\text { refilling of tank } \\
\text { B3 (executed in } \\
\text { step 8) }\end{array}$ \\
\hline & $\begin{array}{l}\text { Washing the } \mathrm{B} 5 \text { tank via the mixer and } \\
\text { the syrup path }\end{array}$ & $\begin{array}{l}\text { Shortened cleaning time of the } \\
\text { B5 tank (washing up to the } \\
\text { maximum level in B3) }\end{array}$ & $\begin{array}{l}\text { Part of the } \\
\text { washing was } \\
\text { carried out in } \\
\text { step } 2\end{array}$ \\
\hline & $\begin{array}{c}\text { Open valves: } 6,7,8,13,14,15,16,17 \\
59,60,67,70,71\end{array}$ & $\begin{array}{c}\text { Open valves: } 6,7,8,13,14,15 \\
16,17,59,60,67,70,71\end{array}$ & \\
\hline & Running pumps: P1, P4 & Running pumps: P1, P4 & \\
\hline \multirow[b]{3}{*}{ Step 7} & $\begin{array}{l}\text { Opening of V7, washing of B6 via the } \\
\text { syrup path (mixer) }\end{array}$ & Opening V7, washing of tank B6 & \\
\hline & Discharging B3 to B5 & Discharging $\mathrm{B} 3$ to $\mathrm{B} 5$ & \\
\hline & $\begin{array}{l}\text { The } \mathrm{P} 3 \text { pump moves the medium to the } \\
\text { B6 tank until it reaches the upper level } \\
\text { (false signals - splashing from the mixer) }\end{array}$ & $\begin{array}{l}\text { Pumping of P3 to tank B6, } \\
\text { regardless of the status of the } \\
\text { upper level sensor }\end{array}$ & $\begin{array}{l}\text { Filling B6 to } \\
\text { the full, no } \\
\text { erroneous } \\
\text { signals } \\
\end{array}$ \\
\hline \multirow{3}{*}{ Step 8} & $\begin{array}{l}\text { B1 filled to the maximum from the CIP } \\
\text { station }\end{array}$ & $\begin{array}{l}\text { Filling of B1 to the maximum } \\
\text { from the CIP station }\end{array}$ & \multirow{3}{*}{$\begin{array}{l}\text { Filling of B3 - } \\
\text { acceleration of } \\
\text { step } 4\end{array}$} \\
\hline & Discharge from B5 to B6 & Discharge of B5 to B6 & \\
\hline & & $\begin{array}{l}\text { Filling tank B3 to the set value } \\
\text { (approx. half of the tank) }\end{array}$ & \\
\hline
\end{tabular}

Improvement of the entire cycle causes the V1 valve to be open almost continuously. Previously, the mixer waited for the end of the step and only then re-opened V1. When the valve is closed, the washing station goes into pause mode and does not count down. This allows the program to execute all the steps of mixer washing (at theoretical continuous operation) approx. 2.5 times per hour.

In Stage III, all aspects of retooling of the production line in question were improved, which allowed to maintain the correctness of the introduced changes. Improving the operation of the mixer washing program was mainly based on the correct introduction of a new program in the PLC. It was critical that activities classified as internal (non-parallel 
operation of the program) worked in the new system. The next stage of process improvement was matching the timely communication with the water treatment station so that the employee knew the right time to turn on the water in the washing process, and to disconnect it after the process was completed.

As part of the improvement process, adequate instructions for the new retooling have also been developed and implemented so that employees can quickly learn what changes they need to adapt to.

\section{Conclusions}

The presented example of optimizing the process of washing the machine, which is part of a carbonated beverage production line clearly indicates that the use of the SMED approach leads to reducing the retooling time and improving resource efficiency. It should be noted that this method was introduced without using additional financial expenses, and was treated as a strictly organizational challenge [7-14].

Upon analyzing the process of mixer washing in terms of time, it was shown that in individual steps, the total single washing time was 5 hours 3 minutes on average, which accounted for about $19 \%$ of the total retooling of the production line. However, after using the SMED method, this process has taken 3 hours 50 minutes. Thus, a saving of 1 hour 13 minutes was obtained after shortening the retooling, which allowed to extend the production process.

In summary, the SMED project carried out is proof of the appropriateness of using lean manufacturing tools in a manufacturing company. Their implementation in the company's organizational area results in a reduction of the unnecessary operational downtime, and in the extension of production time and activities that add value to products. These make the production line work more efficiently, its capacity, utilization and availability are increased. On the other hand, the production company increases its income due to savings, and also benefits from improving the quality of the finished product. The use of continuous improvement tools is therefore the key to success for enterprises and is the first serious step to win the trust of the end customer [15].

\section{References}

1. A. Łazicki, Systemy zarzadzania przedsiębiorstwem- techniki Lean Management, KAIZEN, Wiedza i Praktyka Warszawa, (2014).

2. M. Pomietlorz, Istota koncepcji Lean Manufacturing, Katedra IP, Kielce University of Technology, part IV, 612-621(2015).

3. M. Cupiał, A. Szela g-Sikora, M. Niemiec, M. Agric. Agric. Sci. Proc., 7, 64-6, (2015).

4. P. Chabowski, K. Żywicki, Wpływ organizacji przezbrojeń na efektywność zasobów technicznych; Politechnika Poznańka; KZiIP, 18, 1, 60-70 (2013).

5. S. Shingo, A revolution in manufacturing: the SMED system, Prodactivity Press, Portland-Oregon (1985).

6. J. Matuszek ,T. Kasperek, Zeszyty Naukowe Politechniki Śląskiej, 70, 1909, 287-299 (2014).

7. A. Szeląg-Sikora, J. Sikora, M. Niemiec, Z. Gródek-Szostak, J. Kapusta-Duch, M. Kuboń, M. Komorowska, J. Karcz, J. Sustainability,11, 5612, (2019).

8. Z. Gródek-Szostak, G. Malik, D. Kajrunajtys, A. Szeląg-Sikora, J. Sikora, M. Kuboń, M. Niemiec, J. Kapusta-Duch, J. Sustainability, 11, 4144, (2019). 
9. J. Kapusta-Duch, A. Szeląg-Sikora, J. Sikora, M. Niemiec, Z. Gródek-Szostak, M. Kuboń, T. Leszczyńska, Borczak B. Sustainability, 11, 4008, (2019).

10. M. Niemiec, M. Komorowska, A. Szeląg-Sikora, J. Sikora, M. Kuboń, Z. GródekSzostak, J. Kapusta-Duch. Sustainability, 11, 3913, (2019).

11. A. Onopiuk, A. Półtorak, J. Wyrwisz, M. Moczkowska, A. Stelmasiak, A. Lipińska,A. Szpicer, M. Zalewska, R. Zaremba, M. Kuboń, A. Wierzbicka, CyTA: journal of food, Volume 15, 1, 58-64 (2017).

12. A. Szelag-Sikora, M. Niemiec, Jakub Sikora, M. Chowaniak, In Proceedings of the IX International Scientific Symposium "Farm Machinery and Processes Management in Sustainable Agriculture, Lublin, 365-370, DOI:10.24326/fmpmsa.2017.65 (2017).

13. Z. Gródek-Szostak, A. Szeląg -Sikora, J. Sikora, M. Korenko, Business and Non-profit Organizations Facing Increased Competition and Growing Customers' Demands (Eds. A Ujwary-Gil, A Nalepka), Wyższa Szkoła Biznesu - National-Louis University, Nowy Sacz, 16, 427-439, (2017).

14. J. Sikora, M. Niemiec, A. Szelag-Sikora, M. Kubon, E. Olech, and A. Marczuk, Przemysl Chem. 96, 2275-2278 (2017).

15. T. J. Suteja, Y. Haryono, A.Harianto, E. Rinawiyanti, E3S Web of Conferences, 130, 01031 (2019). 